\title{
Improved Design for a Transseptal Needle
}

\author{
R. L. G. RAINBOW, E. B. RAFTERY ${ }^{\star}$, AND C. M. OAKLEY† \\ From the Department of Medicine (Clinical Cardiology), Postgraduate Medical School and Hammersmith Hospital, \\ Ducane Road, London
}

At a recent meeting of the British Cardiac Society concern was expressed at the risks of piercing the aorta during attempted transseptal catheterization of the left atrium. We wish to describe a needle designed to overcome this risk, which we have used at the Postgraduate Medical School of London for the past three years.

Catheterization of the left side of the heart from the venous route by means of needle puncture of the interatrial septum was introduced in 1959 (Ross, 1959; Cope, 1959). The needle that was designed for this purpose had a wide bore (17 gauge) and allowed the passage of PE 50 polythene tubing through the needle and on into the left atrium and ventricle. The technique was improved by Brockenbrough and Braunwald (1960) who designed a needle that allowed larger catheters to be introduced into the left side of the heart over the needle. The advantages of this system were that the catheter and needle could be introduced by the percutaneous route via the femoral vein, the larger catheter allowed more accurate recordings of pressures, and selective angiocardiography could be carried out through it. Since this needle was employed the technique has come into widespread use as a method of major importance (Braunwald et al., 1962; Miller and Medd, 1964).

However, transseptal catheterization has been associated with complications caused generally by inadvertent puncture either of the free wall of the atrium or of the aorta which is closely related to the anterior part of the interatrial septum. These complications have, in most cases, occurred in the hands of occasional or inexperienced operators but have also been more frequent since the Brockenbrough needle and catheter replaced the original

\footnotetext{
Received September 8, 1966.

* Present address: Cardiac Department, King's College Hospital, London, S.E.5.

† Supported by the British Heart Foundation.
}

Ross needle for general use. Complications occur largely because the more slender Brockenbrough needle is easily deformed, so that the direction of the tip and the indicator at the hub may be at variance. This may result from the tip catching on a structure during manipulation, and is particularly likely if the needle tip is unwisely exposed before the catheter engages the fossa ovalis. The alignment of tip and indicator may be disturbed during cleaning and sterilization, but this should, of course, always be checked before using the instrument.

The transseptal needle designed and produced at the Postgraduate Medical School has all the advantages of the Brockenbrough needle, but being of heavier gauge steel, resists deformity and can be accurately directed within the heart. It consists of a $69 \mathrm{~cm}$. length of stainless steel tubing, $1.85 \mathrm{~mm}$. in diameter, with a luer fitting and a pointer at one end (Fig. 1). At the other end, a $1 \mathrm{~cm}$. length of tubing $1.45 \mathrm{~mm}$. diameter is let into the main shaft, and finally a $0.5 \mathrm{~cm}$. length of tubing 0.95 $\mathrm{mm}$. diameter is let into this to form the tip of the needle. The inner steps between these tubings are bevelled so that the tapering of the internal diameter is not abrupt (Fig. 1). More recently the $0.95 \mathrm{~mm}$. tubing has been put right through the length of the needle. This confers greater strength to the tip and eliminates internal steps as well as being easier to make. The terminal $3 \mathrm{~cm}$. of the needle is then bent around an arc of $35^{\circ}$, and the tip is ground to present a flat surface to the interatrial septum. The catheters are made from lengths of Portex (Portland Plastics) tubing, No. OPP. 270, with an internal diameter of $2 \mathrm{~mm}$., tapered down to fit a Seldinger guide wire $(0.95 \mathrm{~mm}$. diameter).

A further refinement is the use of a fine wire leader with a blunt tip which is longer than the needle and protrudes from its end (Fig. 2). This enables the curved transseptal needle to be advanced easily along the catheter and prevents the 

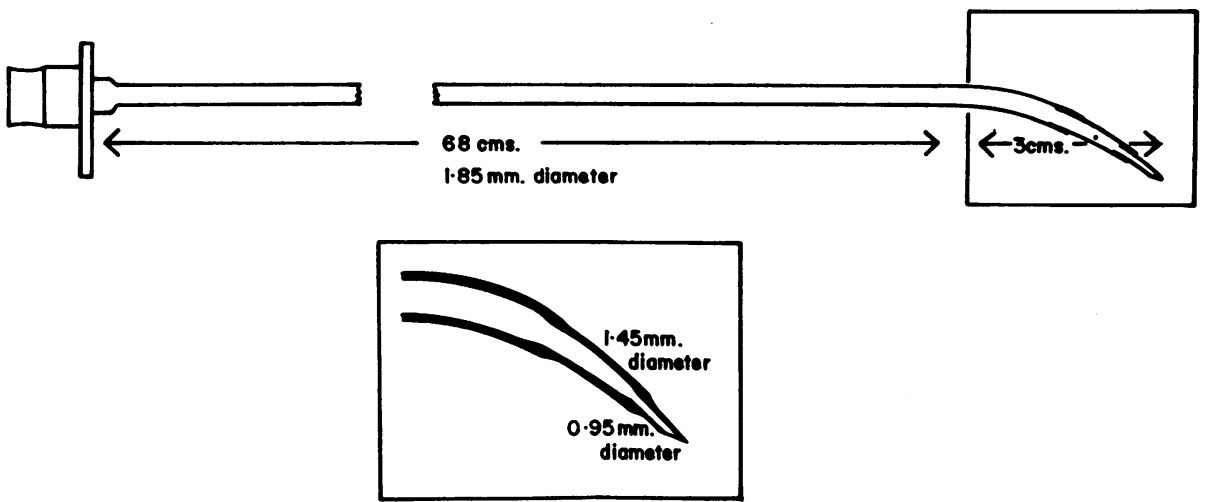

FIG. 1.-Drawing of the needle with an enlarged section of the tip to show the way in which the tapering sections are let into the main shaft of the needle. Note the bevelled internal diameters so that the guide-wire can be easily passed through the tip.

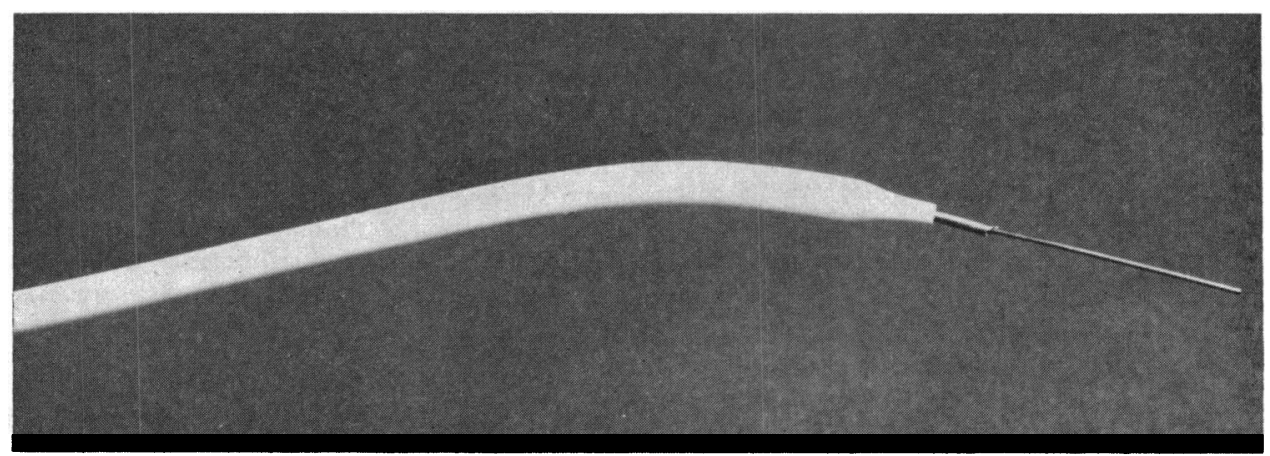

FIG. 2.-Close-up of the catheter with the needle and blunt leader protruding from its tip. Note that the taper of the catheter only allows the terminal $0.5 \mathrm{~cm}$. of the needle to protrude. The leader is not allowed to protrude into the heart, but is withdrawn from the needle when the tip of the catheter is reached. Note also that the leader protrudes a full $2 \mathrm{~cm}$. from the needle in order to straighten out the pre-curved catheter and hold it away from the needle tip as it is advanced.

sharp tip of the needle from perforating the catheter wall. We are grateful to Dr. J. Michael Criley of Johns Hopkins Hospital, Baltimore, for this most valuable addition which was shown to one of us (C.M.O.) who was visiting in 1963.

The thicker steel tubing of the needle shaft in this needle compared with the original Brockenbrough needle makes it difficult for torsion to occur. If the tip becomes embedded during manipulation, the fixation of the needle is immediately apparent. It is not possible as with the unmodified Brockenbrough needle to rotate the proximal end into the desired position while not appreciating that the tip remains fixed and pointing in another direction. Hence the direction of the tip is always accurately controlled. At the same time, the tapered end allows the advantages of the Brockenbrough needle to be retained. This needle has been used for well over 100 transseptal catheterizations in the past three years, during which the root of the aorta has never been pierced.

This modified transseptal needle will shortly become available from: The Genito-Urinary Co., Ltd., Welbeck Street, London W.1.

\section{REFERENCES}

Braunwald, E., Brockenbrough, E. C., Talbert, J. L., Folse, J. R., and Rockoff, S. D. (1962). Selective left heart angiocardiography by the transseptal route. Amer. $\mathcal{F}$. Med., 33, 213.

Brockenbrough, E. C., and Braunwald, E. (1960). A new technic for left ventricular angiocardiography and transseptal left heart catheterization. Amer. F. Cardiol., 6, 1062.

Cope, C. (1959). Technique for transseptal catheterization of the left atrium. Preliminary report. $\mathcal{F}$. thorac. Surg., 37, 482.

Miller, B. L., and Medd, W. E. (1964). Transseptal left heart catheterization. Brit. Heart $\mathcal{F}$., 26, 33.

Ross, J., Jr. (1959). Transseptal left heart catheterization; A new method of left atrial puncture. Ann. Surg., 149, 395. 